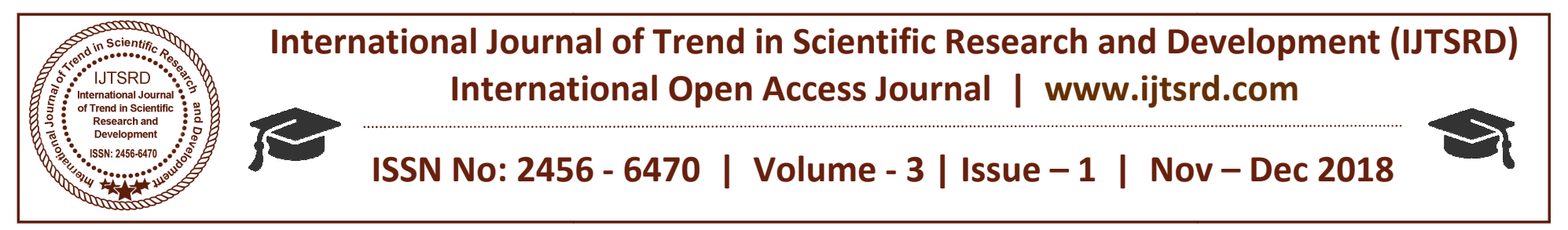

\title{
Local Site Effects Evaluation for Gyobyu Lifeline using Microtremor Measurements
}

\author{
Aye Aye Mar, Kyaw Kyaw \\ PhD Candidate, Civil Department, Yangon Technological University, Yangon, Myanmar
}

\begin{abstract}
Gyobyu pipeline, one of the water supply network system of Yangon region, since this pipeline was constructed in 1940, any seismic design was not considered. During the recent earthquake, 13.3.2017 Taikkyi Earthquake, Magnitude 5.1, pipe supports damage were observed at many locations in the Gyopyu reservoir area. Local site effect is one of the most important aspects in the assessment of seismic hazard and many of the destructive earthquakes in the past have shown that local site conditions have major effects on the ground shaking. In this study, the recorded ambient noise along pipeline was used to compute the $\mathrm{H} / \mathrm{V}$ spectral ratio and then to evaluate the local site effect of the area. The HVSR analysis has been carried out using Cygwin Terminal Software. The predominant frequency (F) ranges between 1.17 to $4.41 \mathrm{~Hz}$ and amplification factor (A) varies from 1.07 to 3.25 . The vulnerability index $(\mathrm{Kg})$ having values ranging from 0.44 to 7.9 . The vulnerability index $(\mathrm{Kg})$ is indicated the soil damage level due to ground motions.
\end{abstract}

KEY WORDS: Predominant frequency, amplification factor, vulnerability index, micro tremor HVSR

\section{INTRODUCTION}

Water supply is vital to the function of an industrialized society and important to emergency response and recovery after earthquakes. There are four reservoirs for Yangon water supply system. One of the reservoirs is Gyobyu reservoir. The water transmission pipeline, however, in Yangon, is installed on the ground supported by the concrete foundation from the reservoir to the downtown terminal point by segmented steel pipe having concrete lining with dresser coupling joint. Gyobyu water pipelines crossed six townships. They are Taikkyi, Hmawbi, Mingalardon, Mayangon, Yankin, and Bahan. Borehole data can't get for all townships. Therefore, microtremor measurement is required along the pipeline.

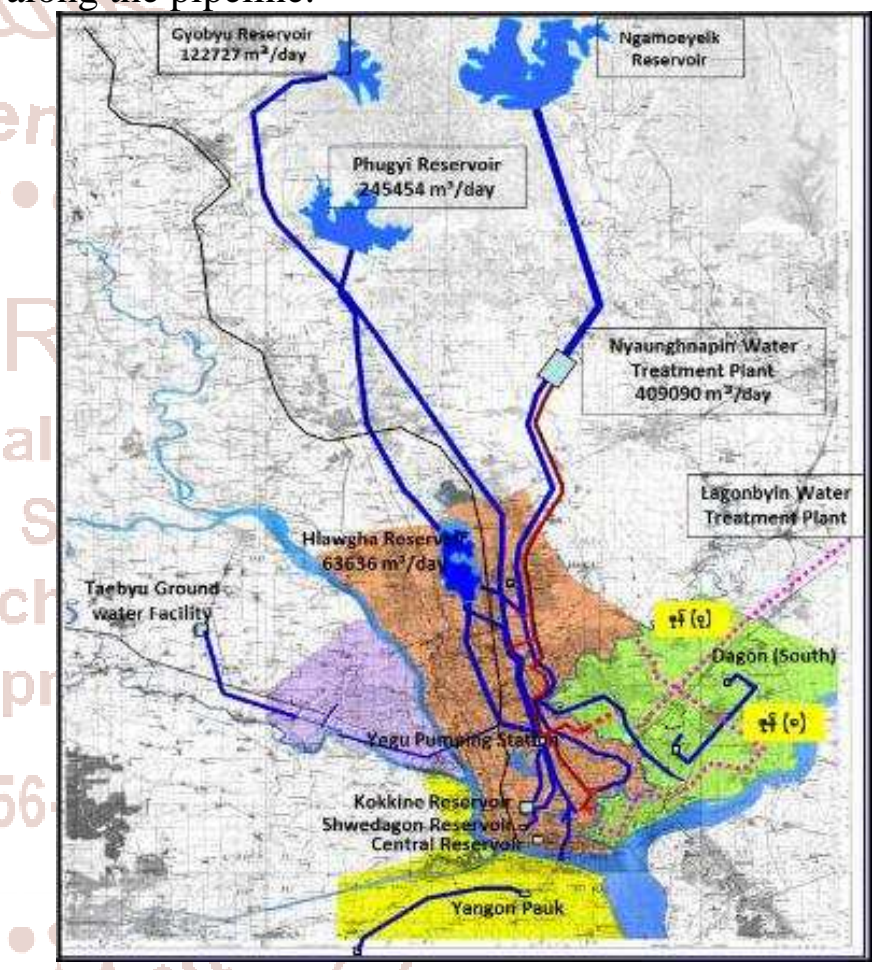

Figure.1 Schematic Configuration of Existing Water System of Yangon (JICA, 2012)

In the study, the present water supply system of Yangon which has been operated over 100 years, all pumping stations in reservoirs and main transmission pipes have already aged and beyond its lifespan, because of the long economic sanction to Myanmar. Gyobyu pipeline was constructed in 1940 and has been operated over 70 years. After that, this pipeline suffered Taikkyi earthquake effect in March 2017. According to the report of responsible person from YCDC, over 200 nubers of pipe supports damaged between Gyobyu reservoir and near Phugyi reservoir (10.5miles). This is the main reason to select this area. 
Gyobyu reservoir is located in Taikkyi Township. The geological structure of Taikkyi area is underlain by alluvial deposits of Bago Yoma fan. Geographically, Taikkyi is situated in central Myanmar. Tectonically, it is located in the Ayeyarwady Delta basin in the west of Sagaing fault. Structurally, the town is located very close to a major strand of the Sagaing fault. [6] The objective of this paper is to investigate the soil conditions of the selected area where microtremor measurements are carried out along Gyobyu lifeline within Taikkyi area. The following figures show the pipe support cracks and their location within Taikkyi area. Each pipe independently moved vertically during earthquake. In recent earthquake, any leakage did not occur. The purpose of this study is to provide fundamental frequency, amplification factor and vulnerability index values for the study area.

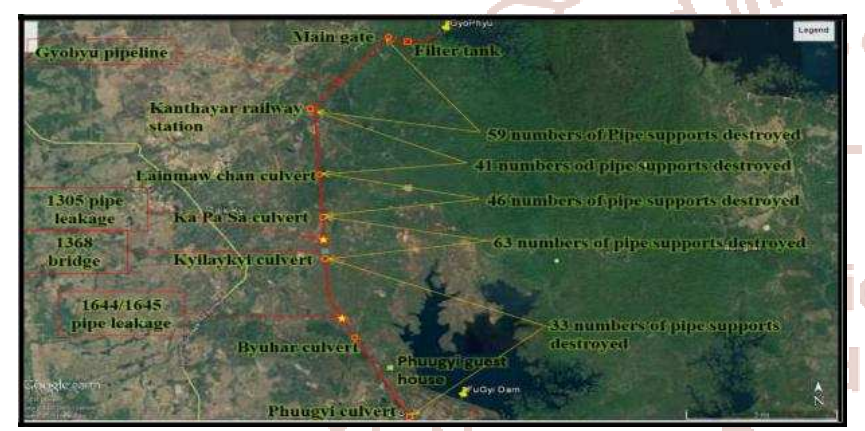

Figure. 2 Location of pipe supports damage within Taikkyi

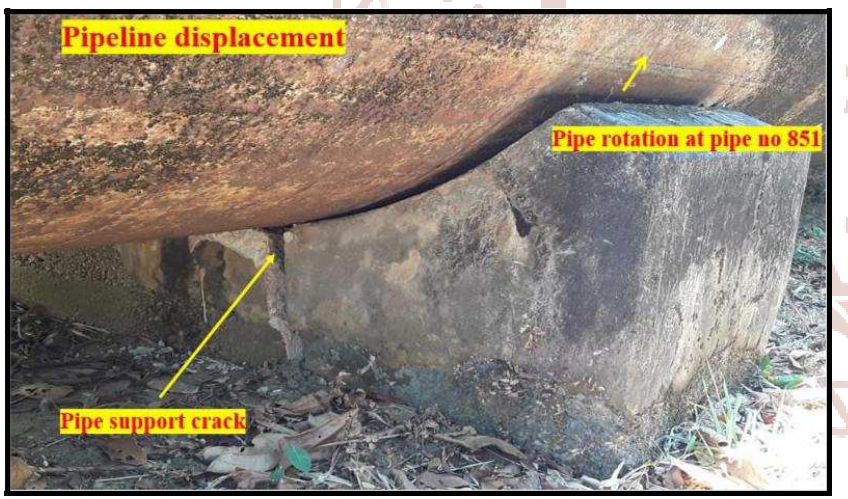

Figure.3 Pipe displacement after Taikkyi earthquake

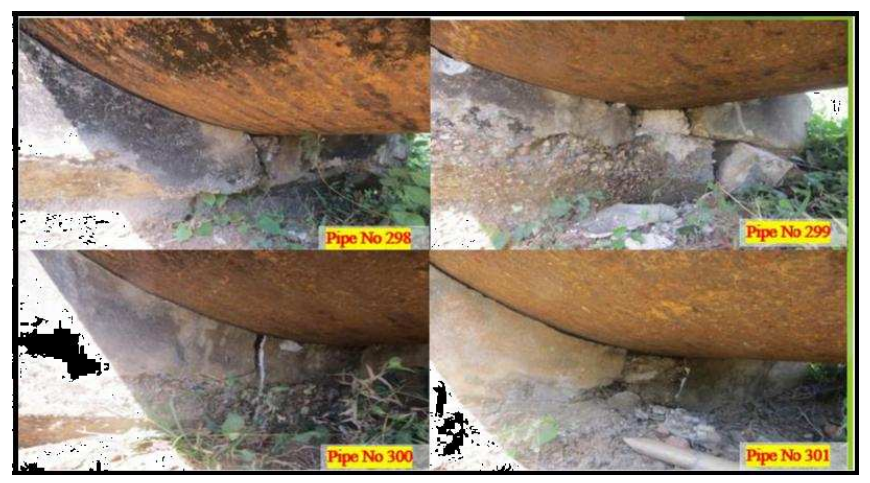

Figure.4 some photos of pipe support damage

\section{METHODOLOGY}

In the present study the micro tremor technique was used to illustrate the local site effect for study area. The single-station method, where a three-component records form a single seismometer is processed to yield a spectrum of horizontal to vertical spectral ratio and these routine spectral techniques can easily be applied to estimate the dominant frequency of vibration of the sedimentary structure. These frequencies of vibration are closely related to the physical features of the site under study, i.e., layer thickness, densities and shear wave velocities. In addition, Microtremor also dominated by surface waves that can be used to determine the Rayleigh wave dispersion curve without the need for an artificial source. Microtremor analysis can be performed using HVSR method (Horizontal to Vertical Spectral Ratio). This method is one of the easiest and most inexpensive ways to understand the properties of the subsurface layer structure without causing disruption to the structure. HVSR method is a method that is used as an indicator of subsurface structure, which shows the relationship between the ratio of the spectrum of $\mathrm{H} / \mathrm{V}$ with the ellipticity curve of Rayleigh waves. Comparison of the spectral of $\mathrm{H} /$ $\mathrm{V}$ is the ratio between the amplitude of Fourier spectral of horizontal and vertical components of microtremor [7]. Rayleigh Ellipticity is the ratio of the amplitude of spectral components of the horizontal to the vertical [8]. Ellipticity curve that is used in earthquake engineering is to determine the fundamental frequency of earthquake locations and is very responsive to the location and depth of a layer. Microtremors can be classified in two major groups according to their frequency values: frequency values greater than $1 \mathrm{~Hz}$ (up to $20 \mathrm{~Hz}$ ) known as "short period" which refer to shallow soil layers. The depths can change between 0 to 100 meters, performed with the effects of the local surface sources such as industry machines, wind, and traffic noises. Frequencies lower than $1 \mathrm{~Hz}$ called as "long period microtremor" which refers to deeper soil layers like rigid rock formation and performed with natural forces such as ebb and tide, wind and underground seismic activities. Nakamura (1989) proposed a method inferring site amplification factors to incident seismic shear waves using microtremor $\mathrm{HV}$ ratio at single site. [9]. In this study, analyzing the site response using the HVSR method and calculated $\mathrm{Kg}$ values based on the microtremor data. Data was reprocessed using Cygwin Terminal software to estimate the Amplification factors (A) and 
fundamental frequency $(\mathrm{F})$ for each observation point. $\mathrm{Kg}$ index was estimated for each site based on Nakamura $(1996,1997,2000)$ technique. [10]

\section{A. Procedure for analysis}

This is the general procedure for calculation of $\mathrm{H} / \mathrm{V}$ spectral ratio from record observation.

\section{Separation of acceleration time historical data}

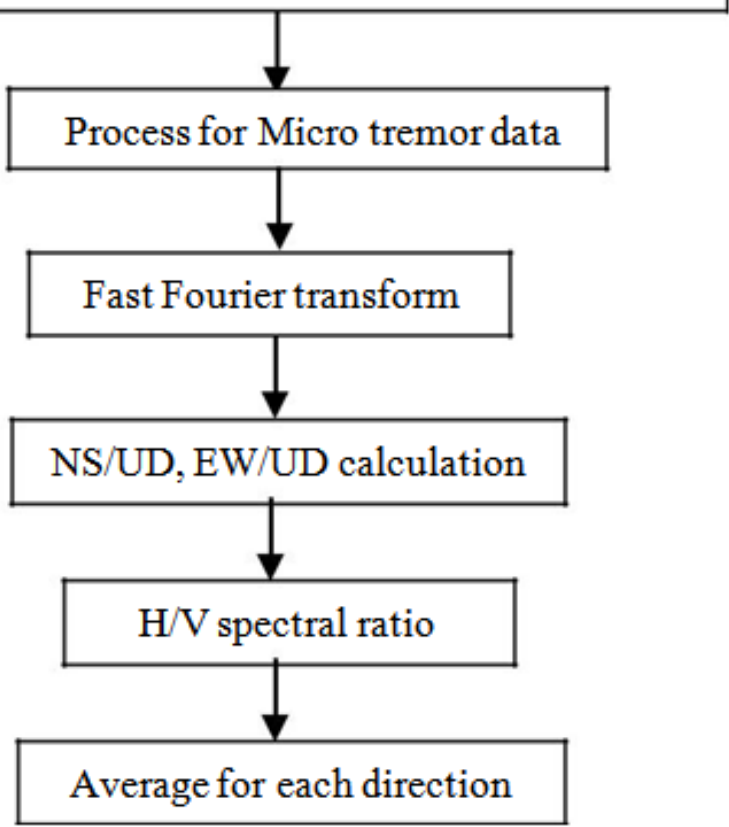

Figure.5 Procedure of $\mathrm{H} / \mathrm{V}$ spectral ratio

After that, the vulnerability index values were calculated in the current study from the microtremor measurements. Seismic vulnerability index $(\mathrm{Kg})$ is one of the simplest physical parameter that could be used to analyze the local geology condition. Seismic vulnerability index was derived from mathematical relationship between the resonance frequency and amplification factor of the ground natural vibration that obtained in horizontal vertical spectral ratio (HVSR) curve analysis. The vulnerability index values are calculated from using the equation (1) that is expressed by Nakamura (1997):

$$
\mathrm{K}_{\mathrm{g}}=\frac{\mathrm{A}^{2}}{\mathrm{~F}}
$$

where $\mathrm{Kg}$ is the vulnerability index, $\mathrm{A}$ is the amplification factor and $\mathrm{F}$ is the fundamental frequency.

$\mathrm{Kg}$ value reflect local site effect and can be considered as an indicator which might be useful in selecting weak point of ground especially along pipeline areas.

\section{MICROTREMOR ALONG PIPELINE}

MEASUREMENTS

Microtremor measurements were performed along pipeline started in November 2017 to still now. The location of all sites is shown in Fig.7. The Global Positioning System (GPS) was used to determine the location and elevation of the measurement sites. The ambient noise vibrations were recorded using LS8800 equipment. The sampling rate was $200 \mathrm{~Hz}$ with a recording duration of 30 minutes. The measurements were taken during the day, the distance between sites is about 500 meters and some sites is about 1 kilometer due to environmental constraints. As for the measurement along pipeline, over the one hundred and forty single station sites, which covered almost the whole area for pipeline, were measured by using GARMIN GPS 78 and LS8800 data logger shown in fig.5.

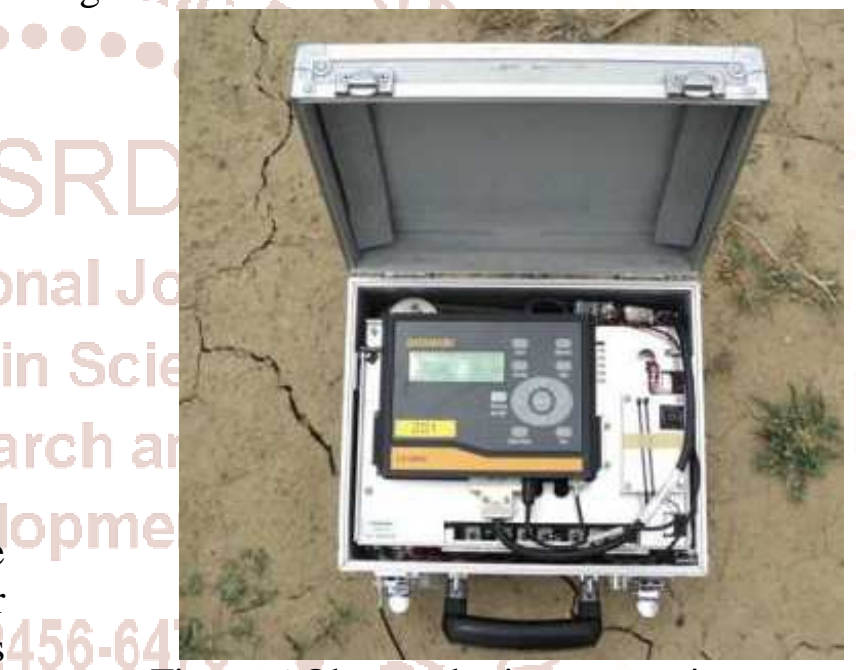

Figure.6 Observed microtremor instrument

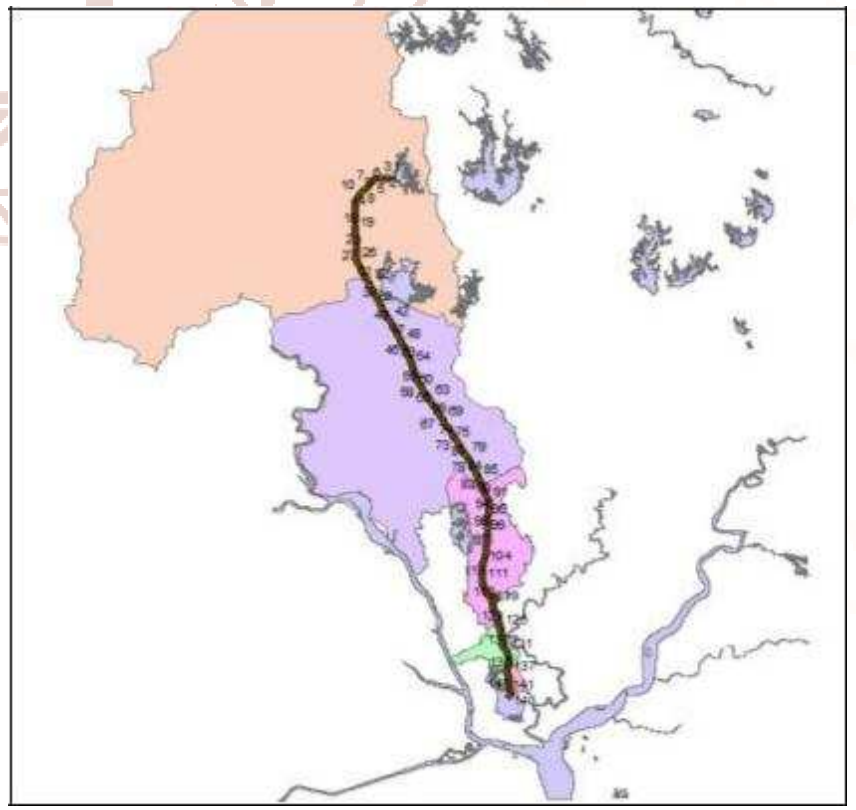

Figure.7 Micro tremor measuring points along Gyobyu pipeline 


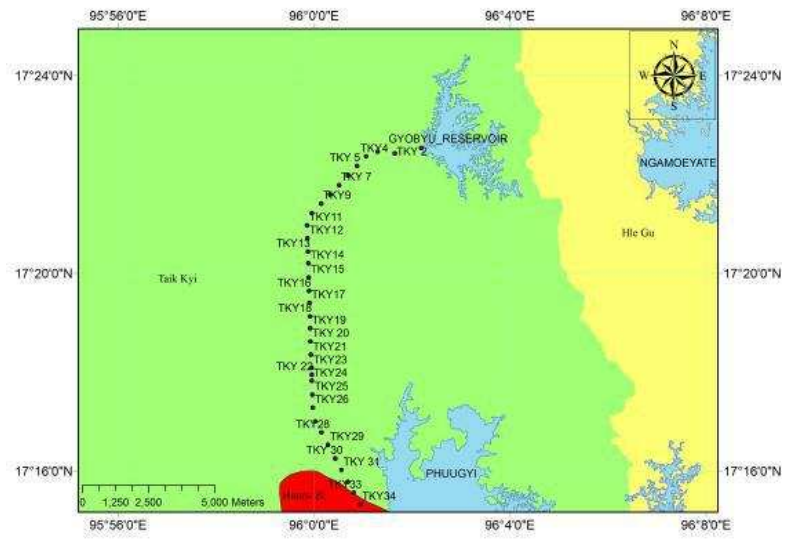

Figure.8 Location of Microtremor measuring points within Taikkyi area

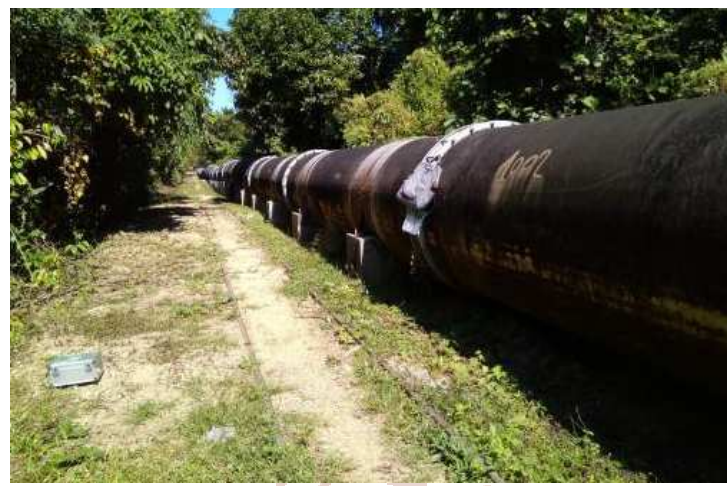

Figure.9 Micro tremor measurement beside pipeline

\section{A. $H / V$ technique and $H / V$ inversion}

The $\mathrm{H} / \mathrm{V}$ analysis is based on the theory first introduced by Nogoshi and Igarashi [1] and further developed by Nakamura [2], who demonstrated that the spectral ratio between the horizontal and vertical components of a microtremor record is related to the fundamental resonant frequency at the study site. the application and interpretation of single point microtremor measurements are very straight forward and convenient, $\mathrm{H} / \mathrm{V}$ method has become very popular in site-specific investigations for study area.

In the case of the $\mathrm{H} / \mathrm{V}$ inversion, the trade-off between depths and velocities cannot be solved using only the H/V curve [3]. Therefore, it becomes necessary to retrieve some of these parameters (VS or thickness) from other independent sources. In this work, reliable data from borehole drills have been used to define the parameter space and specifically, to constrain the number of layers and their corresponding thickness ranges. For all the generated models, the ellipticity of the fundamental mode Rayleigh wave is computed (forward problem) and compared with the empirical $\mathrm{H} / \mathrm{V}$ curve through a misfit function [4], which indicates how far the generated models are from the observed $\mathrm{H} / \mathrm{V}$ results.
IV. RESULTS AND DISCUSSION

A. Distribution of soil natural frequency (F) and amplification factor (A)

The results of microtremor HVRs for a single-station measurement along pipeline within Taikkyi area generally show the following figure that is one-point measurement. The fundamental frequencies, amplification factor and vulnerability index values as shown in Table I.

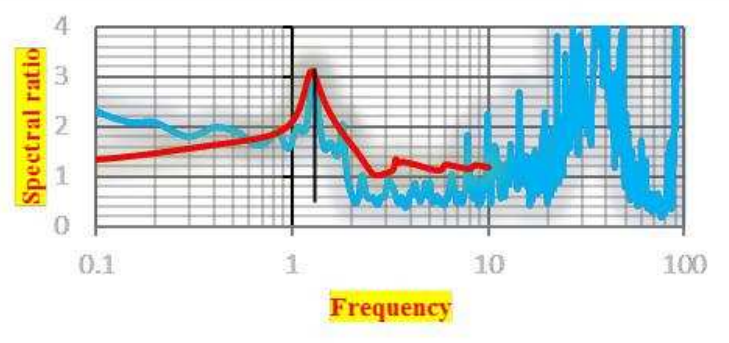

Figure.10 Example of result of HVSR microtremor analysis

And then, the measurement points were shown in an acceptable grid model, which was considered to accomplish good quality contour maps (ArcGIS software) that can display the distribution of the fundamental frequency, amplification factor and vulnerability. The figure. 11 shows the distribution of frequency $(\mathrm{F})$ where the distribution of natural frequency is classified as equal interval, ranging between $1.17-4.41 \mathrm{~Hz}$. It could be noted that frequency (F) is associated with the depth of bedrock. The smaller of frequency $(\mathrm{F})$ value, the greater of depth of bedrock.

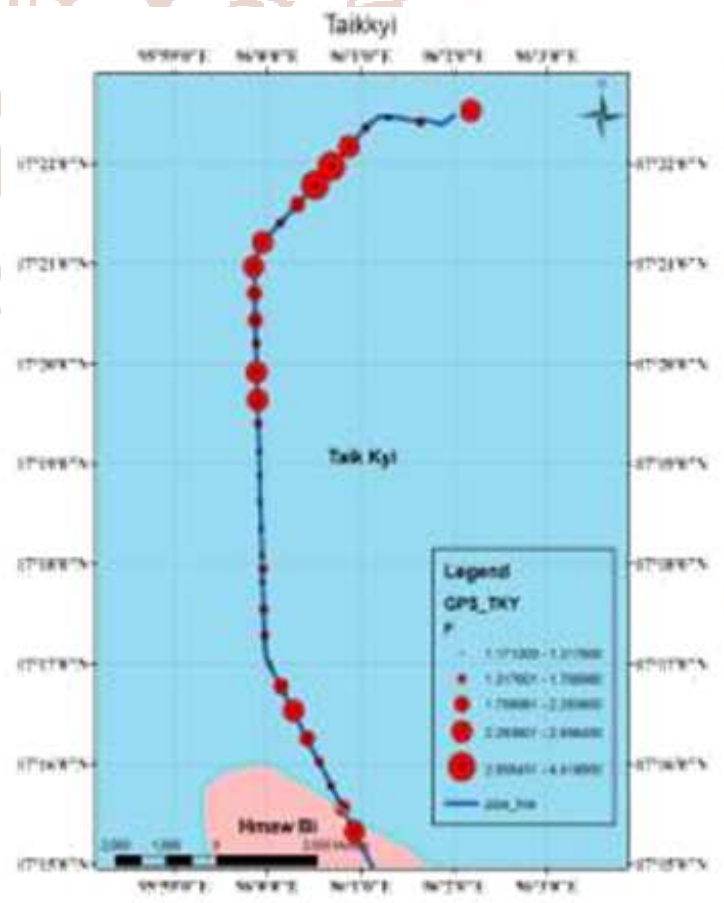

Figure.11 the distribution of fundamental frequency values in the study area 
International Journal of Trend in Scientific Research and Development (IJTSRD) ISSN: 2456-6470

The figure 12 represents the amplification factor (A) or peak ratio HVSR spectrum in investigation sites ranging between 1.07 to 3.25. High amplification factor $(A>3)$ is found in some area. Different value of A might be found in the same value of natural frequency. It can be noted that the variation of $\mathrm{A}$ value is not strongly affected by the soil depth.

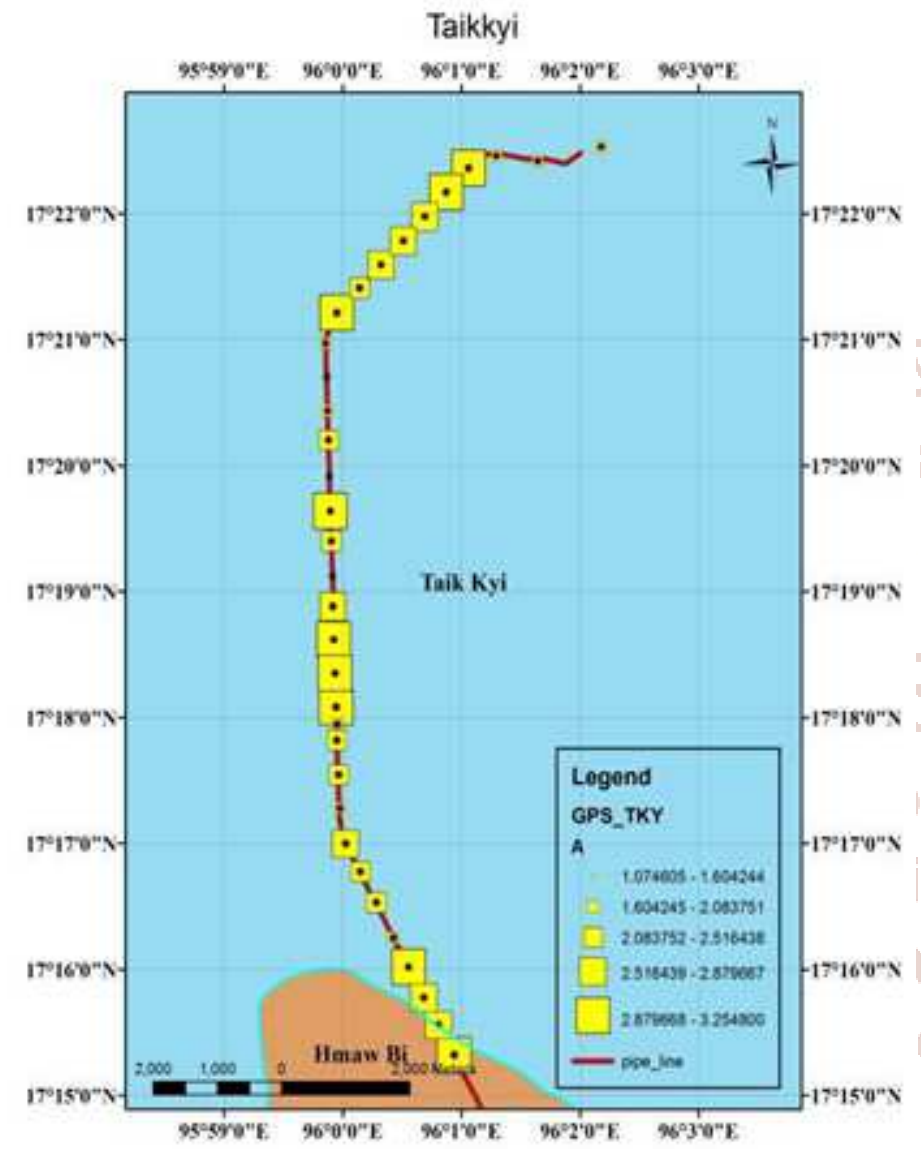

Figure.12 the distribution of amplification factor values in the study area

TABLE.I FREQUENCY, AMPLIFICATION FACTOR AND VULNERABILITY INDEX FOR STUDY AREA

\begin{tabular}{|c|c|c|c|c|c|}
\hline $\begin{array}{c}\text { Point } \\
\text { Nos }\end{array}$ & $\begin{array}{c}\text { Freque } \\
\text { ncy } \\
(\mathbf{F})\end{array}$ & $\begin{array}{c}\text { Amplif } \\
\text { ication } \\
\text { factor } \\
(\mathbf{A})\end{array}$ & $\begin{array}{c}\text { Vulner } \\
\text { ability } \\
\text { index } \\
(\mathbf{K g})\end{array}$ & $\begin{array}{c}\text { VS } \\
(30)\end{array}$ & $\begin{array}{c}\text { Soil } \\
\text { Profile } \\
\text { Type }\end{array}$ \\
\hline 1 & 2.56 & 2.08 & 1.69 & 354.81 & $\mathrm{~S}_{\mathrm{D}}$ \\
\hline 2 & 1.61 & 1.84 & 2.10 & 374.26 & $\mathrm{~S}_{\mathrm{C}}$ \\
\hline 3 & 1.22 & 1.85 & 2.81 & 328.12 & $\mathrm{~S}_{\mathrm{D}}$ \\
\hline 4 & 1.64 & 3.16 & 6.09 & 267.23 & $\mathrm{~S}_{\mathrm{D}}$ \\
\hline 5 & 2.78 & 3.07 & 3.39 & 329.44 & $\mathrm{SD}$ \\
\hline 6 & 3.71 & 2.82 & 2.14 & 404.25 & $\mathrm{~S}_{\mathrm{C}}$ \\
\hline 7 & 4.42 & 2.69 & 1.64 & 473.3 & $\mathrm{~S}_{\mathrm{C}}$ \\
\hline 8 & 2.03 & 2.88 & 4.09 & 355.88 & $\mathrm{~S}_{\mathrm{D}}$ \\
\hline 9 & 1.51 & 2.49 & 4.11 & 270.6 & $\mathrm{~S}_{\mathrm{D}}$ \\
\hline 10 & 2.73 & 3.19 & 3.73 & 235.6 & $\mathrm{SD}$ \\
\hline 11 & 2.86 & 1.93 & 1.30 & 441.11 & $\mathrm{~S}_{\mathrm{C}}$ \\
\hline
\end{tabular}

\begin{tabular}{|c|c|c|c|c|c|}
\hline 12 & 2.29 & 1.46 & 0.93 & 515.27 & $\mathrm{~S}_{\mathrm{C}}$ \\
\hline 13 & 1.88 & 1.86 & 1.84 & 329.47 & $\mathrm{~S}_{\mathrm{D}}$ \\
\hline 14 & 1.47 & 2.25 & 3.44 & 269.66 & $\mathrm{~S}_{\mathrm{D}}$ \\
\hline 15 & 2.64 & 1.07 & 0.43 & 333.7 & $\mathrm{SD}$ \\
\hline 16 & 2.78 & 2.95 & 3.13 & 397.74 & $\mathrm{~S}_{\mathrm{C}}$ \\
\hline 17 & 1.68 & 2.38 & 3.37 & 222.99 & $\mathrm{~S}_{\mathrm{D}}$ \\
\hline 18 & 1.24 & 1.6 & 2.06 & 450.5 & $\mathrm{~S}_{\mathrm{C}}$ \\
\hline 19 & 1.17 & 2.72 & 6.32 & 173.11 & $\mathrm{~S}_{\mathrm{E}}$ \\
\hline 20 & 1.27 & 3.17 & 7.91 & 135.47 & $\mathrm{SE}$ \\
\hline 21 & 1.22 & 2.96 & 7.18 & 139.01 & $\mathrm{~S}_{\mathrm{E}}$ \\
\hline 22 & 1.71 & 1.87 & 2.04 & 314.02 & $\mathrm{~S}_{\mathrm{D}}$ \\
\hline 23 & 1.25 & 3.11 & 7.74 & 234.54 & $\mathrm{~S}_{\mathrm{D}}$ \\
\hline 24 & 1.19 & 2.32 & 4.52 & 227.27 & $\mathrm{SD}$ \\
\hline 25 & 1.56 & 2.19 & 3.07 & 230.77 & $\mathrm{~S}_{\mathrm{D}}$ \\
\hline 26 & 1.46 & 2.05 & 2.88 & 275.51 & $\mathrm{~S}_{\mathrm{D}}$ \\
\hline 27 & 1.32 & 2.65 & 5.32 & 169.86 & $\mathrm{~S}_{\mathrm{E}}$ \\
\hline 28 & 2 & 2.52 & 3.18 & 267.61 & $\mathrm{~S}_{\mathrm{D}}$ \\
\hline 29 & 2.54 & 2.31 & 2.10 & 237.96 & $\mathrm{SD}$ \\
\hline 30 & 1.88 & 1.73 & 1.59 & 360 & $\mathrm{~S}_{\mathrm{D}}$ \\
\hline 31 & 1.66 & 3.25 & 6.36 & 156.13 & $\mathrm{SE}$ \\
\hline 32 & 1.46 & 2.55 & 4.45 & 270.61 & $\mathrm{~S}_{\mathrm{D}}$ \\
\hline 33 & 2.1 & 2.69 & 3.45 & 470.31 & $\mathrm{SC}$ \\
\hline 34 & 2.54 & 3.02 & 3.59 & 325.44 & $\mathrm{~S}_{\mathrm{D}}$ \\
\hline & & & & & \\
\hline
\end{tabular}

B. Distribution of Soil Vulnerability Index (Kg)

The use of microtremor was later expanded to identify the vulnerability index for ground (Nakamura, 1996, 1997, 2000, 2009; Daryono et al., 2009) [11]. Nakamura (1997) introduced a vulnerability index parameter $(\mathrm{Kg})$, which combined $\mathrm{A}$ and $\mathrm{F}$ to determine soil damage level due to the local site effects. Thus, $\mathrm{Kg}$ can be considered as an index to indicated easiness of deformation of points which is expected useful to detect weak points of the ground. To estimate soil vulnerability index $(\mathrm{Kg})$, the value of shear strain $(\gamma)$ need to be considered (Nguyen, et.al., 2004). The vulnerability index $(\mathrm{Kg})$ is limited in that from $\gamma=1000 \times 10^{-6}$ ground begins to show nonlinear character and in $\gamma>10,000 \times 10^{-6}$ large deformation and collapse occur. Nakamura (1997) had written the equation 2 that as follows:

$$
r=K_{g} \times \alpha_{b}\left(\text { in } 10^{-6}\right) \& K_{g} \cong \frac{A^{2}}{F}\left(\text { in } 10^{-6}\right)
$$

where $\alpha b$ is the acceleration of basement ground, $\mathrm{A}$ is amplification factor, $\mathrm{F}$ is the fundamental frequency of surface ground. Based on the above equation, the effective strain can be estimated by multiplying $\mathrm{Kg}$ value with maximum acceleration of basement ground $\alpha b$ in $\mathrm{Gal}\left(\mathrm{cm} / \mathrm{s}^{2}\right)$ and can be considered as an index to 
indicate easiness of deformation of measured points, which is expected to be useful to detect weak points of the ground. Figure. 13 shows the distribution of vulnerability index $(\mathrm{Kg})$ having values ranging from 0.44 to 7.9 . In this study, $\alpha \mathrm{b}=0.2 \mathrm{~g}(200 \mathrm{Gal})$ and $\mathrm{V}$ $=800 \mathrm{~m} / \mathrm{s}$, for $\gamma>1000 \times 10^{-6}$ then the $\mathrm{Kg}$ value > 5; and for $\gamma>10,000 \times 10^{-6}$ the $\mathrm{Kg}$ value $>50$. Based on the above criteria, for the value of $\mathrm{Kg} 50$ was not found and $\mathrm{Kg}>5$ was found at some points in this study area. Some area are found that vulnerability index $(\mathrm{Kg})<5$. The minimum value of $(\mathrm{Kg})$ is 0.43 and maximum value of $(\mathrm{Kg})$ is 7.9 for this study area.

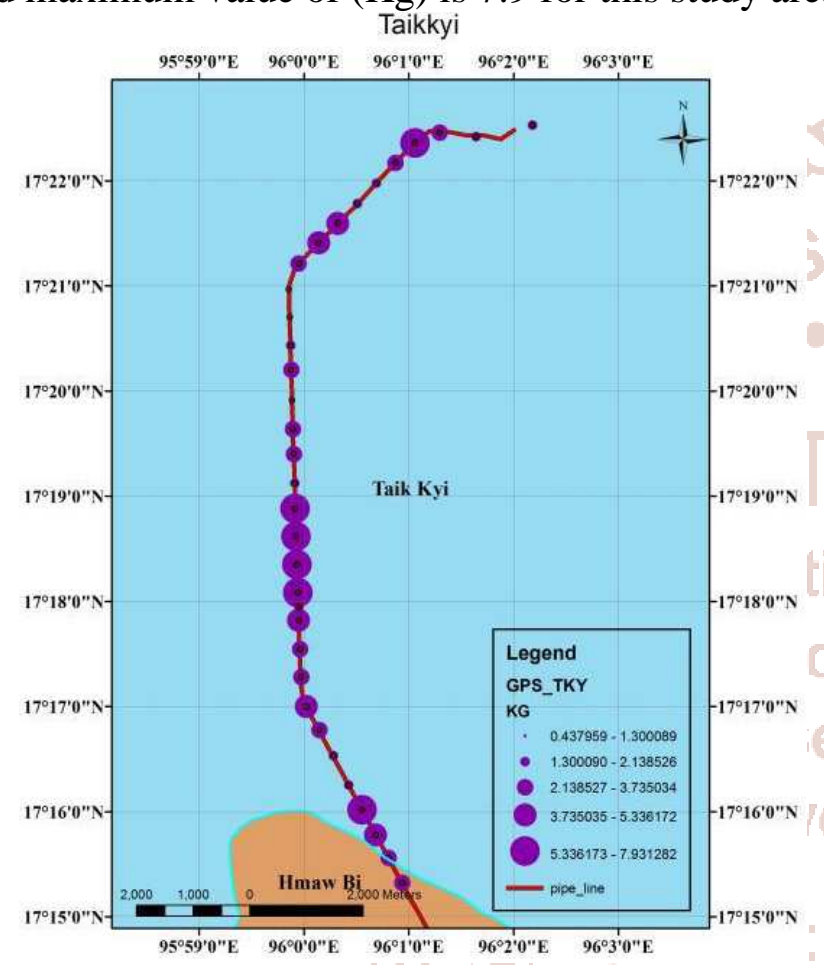

Figure.13 The distribution of vulnerability index $(\mathrm{Kg})$ values in the study area

The following figures show frequencies, amplification factor and vulnerability $(\mathrm{Kg})$ value for each site.

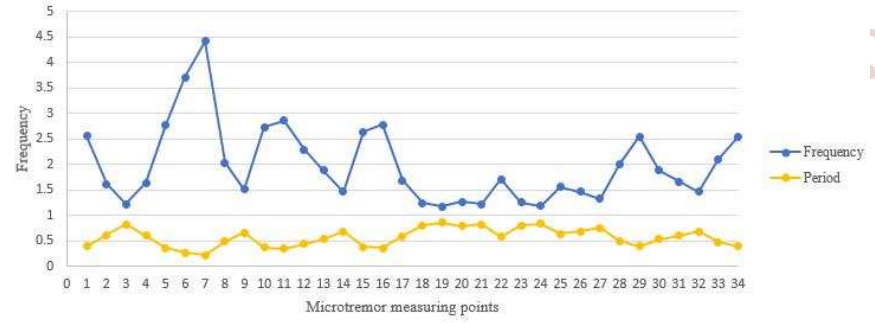

(a)

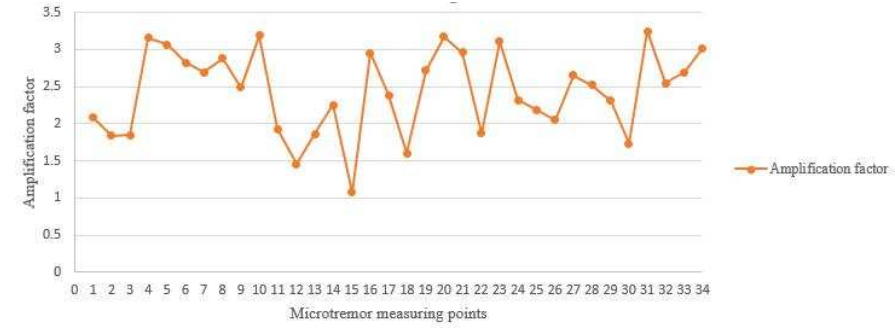

(b)

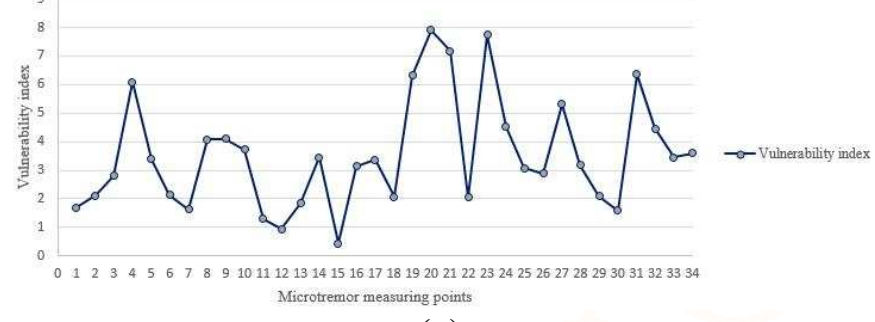

(c)

Fig.14 (a) Frequencies and Period (b) amplification factor (c) vulnerability (Kg) value for each site

\section{Comparison between actual deformation and measured results}

In this study, table 1 shows the amplification factor, frequency, shear waves and Soil Profile Type for study area. It was found that the higher vulnerability index (Kg) at the measured points 4, 19, 20, 21, 23, 27 and 31 as shown in Fig. 8. Almost of these points are soil profile type SE. The pipe supports damage were found between these points. The worst damages were found between 5 to 10 miles far from Gyobyu reservoir. The frequencies $(F)$ of above 6 points were lower than $1.7 \mathrm{HZ}$ values and the vulnerability indexes $(\mathrm{Kg})$ were great $\mathrm{Kg}>5$. The vulnerability index $\mathrm{Kg}$ is significantly related to the damage of pipe supports when the ground is not severely deformation. a result of the study of all measured points are shown in Fig. 11, 12, 13 and 14.

\section{Me CONCLUSION}

The microtremor records along Gyobyu pipeline are analyzed for 34 positions with Taikkyi area. An attempt has been made to interpret variations of microtremor $\mathrm{H} / \mathrm{V}$ spectral ratios in terms of the local site effect. The main conclusions can be summarized as follows:

Seismic waves travel through different materials at different speeds.

$>$ Seismic waves travel through different materials with different amplitude.

Bedrock has high frequency low-amplitude waves (less destructive).

$>$ Sediment has low-frequency high amplitude waves (more destructive).

Therefore, the observe amplitude and frequency are reasonable for this concept. Site 4, 19, 20, 21, 22, 23, 27, 31 are more damage pipe support than other site. From the results, higher amplification is more destructive at pipe support in actual damage condition. There was not found pipe support damage 
at that point. In higher value of $\mathrm{Kg}(\mathrm{Kg}>5)$ in some points, there are more damage of pipe supports other than points $(\mathrm{Kg}<5)$ in recent earthquake. These results show that the weak location of the soil for this area, corresponding to recent earthquake, can retrofit the pipe supports at these location which reveal the necessity for an appropriate emergency management program.

\section{ACKNOWLEDGMENT}

I would like to appreciate greatly to Dr. Nyan Myint Kyaw, Head of Civil Engineering Department, YTU, who gave me the permission to do this research, and Dr. Kyaw Kyaw, Civil Engineering Department, YTU, who supervised my whole work and Engineers, Water Work Association Department, YCDC, who helped and gave any necessary data for my study case.

\section{REFERENCES}

1. NogoshiM, IgarashiT. On the amplitude characteristics of microtremor (Part2). J Seismol Soc Jpn 1971; 24:26-40 (in Japanese with English abstract).

2. NakamuraY.A method for dynamic characteristics estimation of subsurface using microtremor on the ground surface. Q Rep Railw Tech Res Inst 1989; 30:250-363.

3. Scherbaum F, HinzenK-G, Ohrnberger $M$. Determination of shallow shear wave velocity profiles in the Cologne/ Germany are a using ambient vibrations. GeophysJInt2003; 152:597612.
4. Wathelet M, Jongmans D, Ohrnberger $\mathbf{M}$. Surface-wave inversion using a direct search algorithm and its application to ambient vibration measurements. Near Surf Geophys2004;2(4):21121.

5. Sánchez-Sesma, F.J., et al. (2011): Theory for microtremor $\mathrm{H} / \mathrm{V}$ spectral ratio: application for a layered medium, GJI, DOI: 10.1111/j.1365246X.2011.05064.x.

6. The 2017 M 5.1 Taikkyi earthquake, Tech Digest Quarterly Magazine Vol. 9/ No.4, July, 2017 --page: 114

7. A. Susilo and P. Winoto, "Rudyanto A. Microtremor Analysis of Brawijaya University Area Using Horizontal to Vertical Spectral Ratio Methods," Jurnal Geofisika [J], vol. 1, 2010, PP. 17-24

8. A. Keiiti, "Richards P. G. Quantitative Seismology," University Science Book, Sausalito, California, the USA,2002

9. H. Dindar, Vulnerability Index Assessment using Neural Networks (VIANN): A case study of Nicosia, Cyprus, 4th International GeoAdvances Workshop, 14-15 October 2017, Safranbolu, Karabuk, Turkey

10. E. Fergany, K. Omar, Liquefaction potential of Nile delta, Egypt, NRIAG Journal of Astronomy and Geophysics 6 (2017) 60-67, http://dx.doi.org/10.1016/j.nrjag.2017.01.004 